\title{
PEMBUATAN ANTENA MIKROSTRIP PHASED ARRAY DENGAN PENGATURAN FASA MENGGUNAKAN VARIASI PANJANG SALURAN CATU
}

Oleh :

Firdaus

Staf Pengajar Jurusan Teknik Elektro Politeknik Negeri Padang

\section{ABSTRACT}

A microstrip phased array width phase is controlled by length of line feeder is presented in this paper for application in RADAR system. The microstrip array antenna is built from dipolelike individual elemen at center frequency $650 \mathrm{MHz}$. Five different length transmission lines are used to change current phase feeding in to the antenna which is $2 \lambda$, $2.125 \lambda, 2.025 \lambda$, and $2.5 \lambda$. The measured result reveal exelent agreement width the simaltions. The different length of transmission line able to change the radiation pattern which are $60^{\circ}, 150^{\circ}, 210^{\circ}$ dan $0^{\circ}$.

Keywords : Microstrip, Phase Array, Phase Shifter

\section{PENDAHULUAN}

Antenna phased array merupakan antenna yang tersusunan dari beberapa buah elemen antenna dengan fasa antar elemen adalah variabel sehingga pola radiasi antenna bisa berubah dengan perubahan fasa[1]. Antena ini diaplikasikan secara luas pada system telekomunikasi seperti radar, militer dan RFID. Keuntungan penggunaan antenna phased array pada radar adalah bahwa antenna tidak perlu diputar secara fisik tetapi cukup secara elektrik sehingga lebih efisien dari segi biaya dan daya yang digunakan untuk memutar rotator antena. Sedangkan pada tag RFID tidak perlu benar-benar mengarah pada perangkat detector, tetapi perangkat detector dapat mengarahkan polaradiasi kearah posisi tag di tempatkan. Secara sederhana penggeseran fasa dapat dilakukan dengan memberikan panjang kabel catu yang berbeda untuk masingmasing elemen antenna[1]. Berbagai pengeser fasa sudah banyak diteliti sebagaimana pada [2] membuat pengeser fasa 3 bit dengan penggeseran fasa output dilakukan dengan memvariasikan panjang kabel. Dengan metoda ini dihasilkan penggeser fasa yang berukuran cukup besar sehingga tidak efisien apabila digabungkan dengan perangkat telekomunikasi. Pengendalikan fasa antenna array tiga elemen dengan atena individual antenna dipole telah dilakukan pada [3]. Dengan frekuensi $650 \mathrm{MHz}$ dan menggunakan penggeser fasa pada [2]. Polaradiasi sudah dapat diarahkan ke beberapa sudut, tetapi ada perubahan daya pancar pada masing-masing sudut akibat coupling antar kabel yang tidak bisa diprediksi secara akurat.

Untuk tujuan tertentu diiginkan antenna yang berukuran kecil dan ringan sehingga mudah dipasang pada perangkat telekomunikasi pada pesawat terbang, kapal laut atau kendaraan. Dimana dimensi antenna diharapkan 
memudahkan pemasangan antenna pada badan pesawat kapal atau kendaraan darat lainnya. Untuk tujuan ini dikembangkan antenna mikrostrip [4] dimana elemen antenna dibuat dalam bentuk strip kecil pada PCB.

Berdasarkan teori kopling saluran transmisi pada [5] memungkinkan dihitung impedansi dan kapasitansi saluran mikrostrip secara akurat dan saluran transmisi dapat dimodelkan atau digambarkan berupa rangkaian ekivalen R L dan C. Sehingga impedansi dan pengaruh kopling pada saluran dapat direncanakan dengan baik. Dengan demikian memungkinkan dibuat penggeser fasa dengan ukuran yang lebih kecil dan dapat dipasang secara efisien pada perangkat telekomunikasi []dan kehilangan daya akibat perubahan impedansi pada masing-masing fasa dapat dikurangi dan biaya fabrikasi bisa diperkecil. Dengan bantuan software IE3D desain saluran transmisi, phase shifter dan atena mikrostrip dapat dilakukan dan disimulasikan dengan akurat sebelum dilakukan fabrikasi sebagaimana yang telah dilakukan pada [6].

Pada makalah ini dibuat phased array antenna yang didesain langsung bersama penggeser fasa dalam bentuk mikrostrip. Sehingga kinerja antenna array diharapkan dapat ditingkatkan dari hasil yang dicapai pada [2] dan [3] dimana pengarahan polaradiasi akan lebih baik dan tidak ada penurunan daya pancar dengan desain antenna mikrostrip dan phase shifter dengan mikrostrip line substrat PCB dengan biaya minimal dan ukuran yang lebih kecil.

\section{TINJAUAN PUSTAKA}

\section{Antena Mikrostrip[3]}

Pada aplikasi pesawat antariksa, pesawat udara, pengendalian misil, dibutuhkan antena dengan berat yang ringan, ukuran yang kecil/tipis, mudah dipasang da berbentuk aerodinamis. Untuk tujuan ini maka dapat digunakan antena mikrostrip. Dengan menambahkan beban diantara patch dan ground plane berupa dioda pin maupun varactor, maka elemen adaptif dengan frekuensi resonansi variabel maka impedansi, polaradiasi, polarisasi dapat di rencanakan.

Bentuk antena mikrostrip ditunjukkan pada gambar 10 terdiri dari strip kecil yang sangat tipis yang disebut patch dengan ukuran $\mathrm{h}<<\lambda_{\mathrm{O}}$ biasanya sebesar $0.003 \lambda_{\mathrm{O}} \leq$ $\mathrm{h} \leq 0.05 \lambda_{\mathrm{O}}$.. Patch mikrostrip dedesain sedemikian rupa sehingga polaradiasi maksimum normal terhadap permukaan patch. Untuk patch rectangular panjang $\mathrm{L}$ biasanya sebesar $\lambda_{\mathrm{O}} / 3<\mathrm{L}<\lambda_{\mathrm{O}} / 2$.

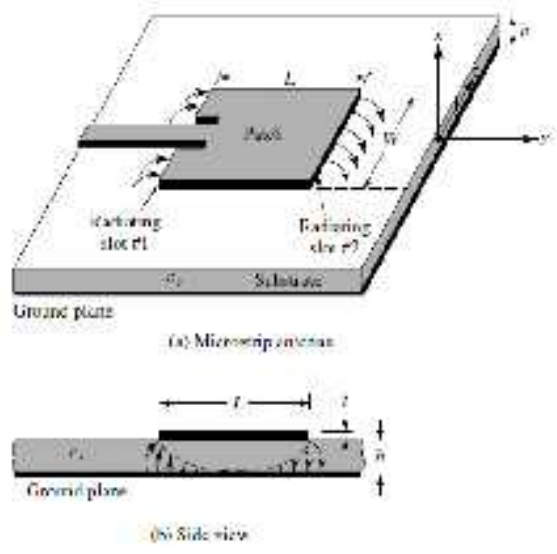

Gambar 1. Antena Mikrostrip

Ada bebarapa cara yang dapat digunakan untuk mencatu antenna mikrostrip. Empat cara yang paling popular adalah microstrip line, coaxial probe, aperture coupling, dan proximity coupling. Keempat cara ini dapat dimodelkan dalam rangkaian ekivalen $\mathrm{R}, \mathrm{L}$ dan $\mathrm{C}$ sehingga memungkinkan mendesain saluran catu agar sesuai dengan patch 

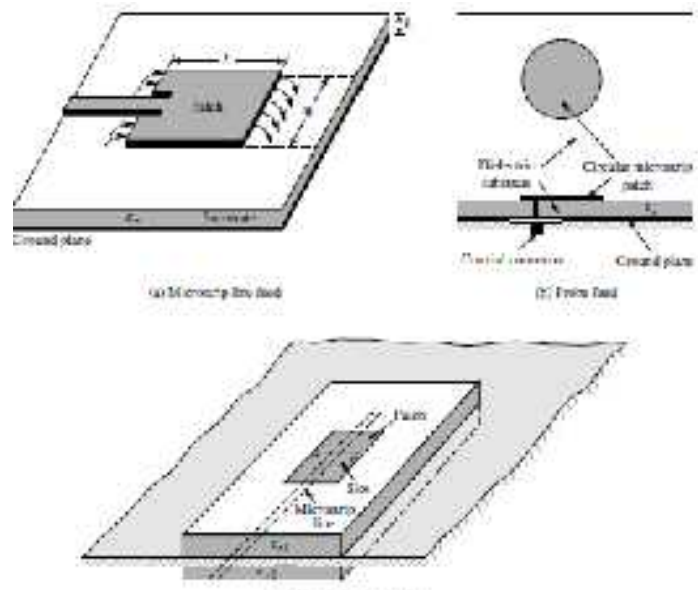

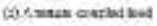

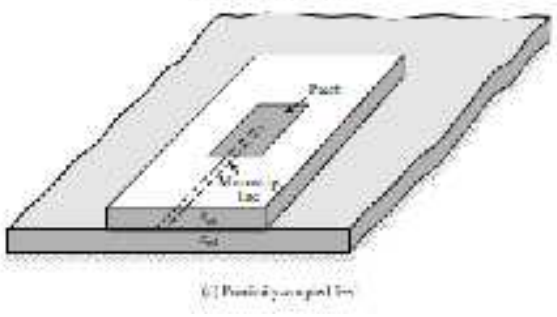

Gambar 2. Saluran Catu Antena Mikrostrip

\section{Switched line phase Shifter}

Phase shifter adalah suatu perangkat untuk menggeser atau menambah fasa dari sinyal yang ditransmisikan pada system. Salah satu metoda yang sederhana untuk menggeser fasa sinyal adalah Switched line phase shifter ditunjukkan pada gambar 3. Saklar SPDT digunakan untuk mengalihkan antara saluran transmisi yang mempunyai panjang yang berbeda. Berbeda dengan dua model sebelumnya, delay yang dihasilkan sesuai dengan dengan waktu (true time delay) sehingga memungkinkan menghasilkan fasa respon fasa yang sesuai dengan frekuensi. Pergeseran fasa diberikan oleh :

$$
\Delta \varphi \approx \beta(L 2-L 1)
$$

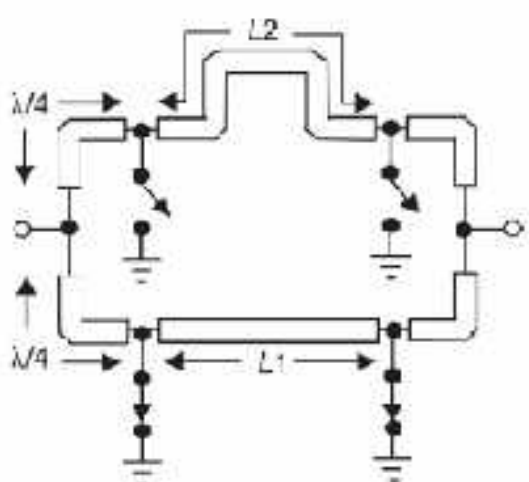

Gambar 3. Switch line phase shifter.

\section{DESAIN ANTENA}

Antena mikrostrip didesain pada frekuensi $650 \mathrm{MHz}$ dengan menggunakan software IE3D dengan bentuk menyerupai antenna dipole $1 / 2$ lambda. Ukuran desain antenna dalam $\mathrm{mm}$ ditunjukkan pada gambar. Selanjutnya dilakukan simulasi return loss Antena dan didapat kurva return loss sebagaimana yang ditunjukkan pada gambar 5. Dimana antenna bekerja dengan baik pada frekuensi $650 \mathrm{MHz}$ dengan nilai return loss sebesar $-38 \mathrm{~dB}$. Ini menunjukkan antenna hasil desain akan memancarkan daya maksimum dengan return loss yang sangat kecil.

Selanjutnya untuk tujuan penelitian mendapatkan antenna yang bisa diarahkan polaradiasinya maka selanjut nya antenna disusun dalam bentuk array.

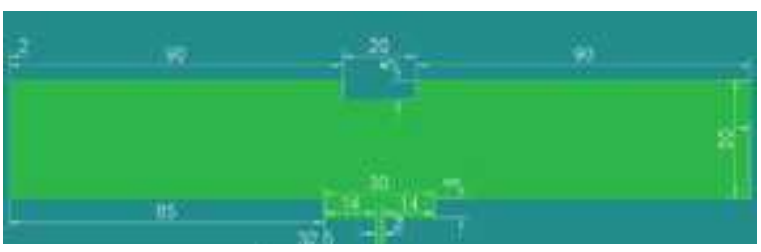

Gambar 4. Desain antenna mikrostrip

Antena hasil desain pada gambar 4 selanjutnya disusun dalam struktur array linier 4 elemen sebagaimana yang ditunjukkan pada gambar 6 . 


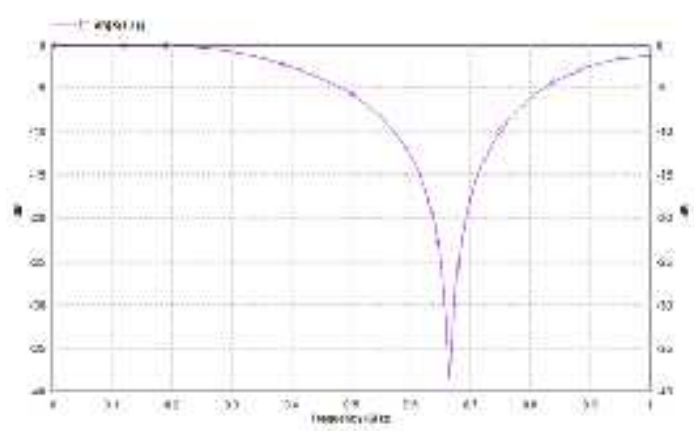

Gambar 5 Return loss antenna mikrostrip hasil desain

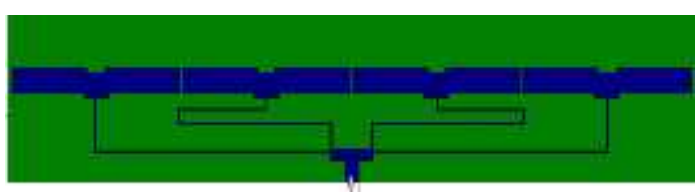

(a) Panjang saluran $2 \lambda$

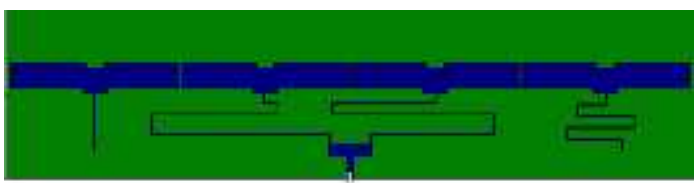

(b) Selisih Panjang saluran $0.025 \lambda$

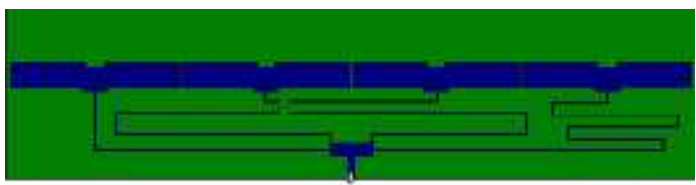

(c) Selisih Panjang saluran $0.5 \lambda$

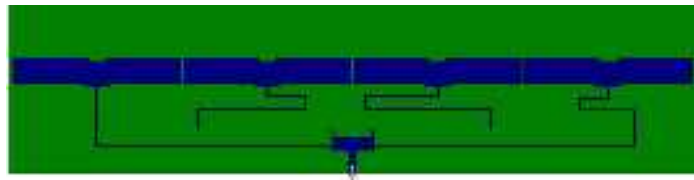

(d) Selisih Panjang saluran $0.5 \lambda$

Gambar 6 Antena mikrostrip hasil desain untuk panjang saluran yang berbeda.

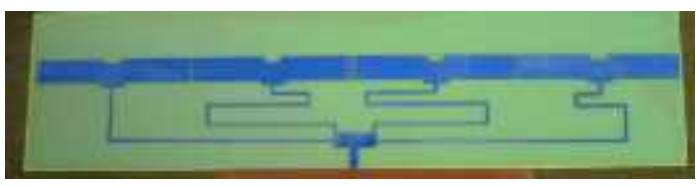

Gambar 7. Fabrikasi Antena

\section{HASIL PENGUJIAN FABRIKASI}

\section{ANTENA}

Tahap berikutnya adalah pengujian dari fabrikasi antenna hasil desain. Setiap antenna dicetak pada PCB double layer FR 4. Sebagaimana yang ditunjukkan pada gambar 6 .

\section{Respon Frekuensi}

Untuk pengukuran antenna hasil fabrikasi ditempatkan sebagai antenna penerima, dengan alasan impedansi antenna belum bisa di ukur dengan pasti sehingga kondisi antenna yang tidak match dengan saluran dikhawatirkan akan merusah perangkat generator jika antenna digunakan sebagai pemancar. Range pengukuran respon frekuensi mulai dari $400 \mathrm{MHz}$ sampai $770 \mathrm{MHz}$ dimana pada kedua frekuensi tersebut didapat hasil pengukuran yang minimum sehingga frekuensi kerja berkisar antara $400 \mathrm{MHz}$ sampai $770 \mathrm{MHz}$. Pada gambar 5.11 ditunjukkan respon frekuensi gabungan untuk keempat antenna hasil fabrikasi. Dimana secara berurut saluran 1 sampai 4 adalah antena dengan saluran sama, selisih $0,125 \lambda, 0.25 \lambda, 0,5 \lambda$.

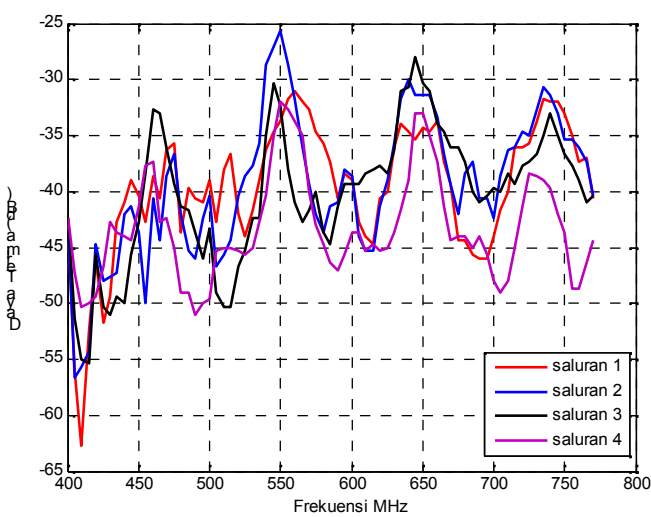

Gambar 8 Respon Frekuensi Antena Array Mikrostrip

Dari gambar 8 dapat dilihat respon frekuensi mempunyai trend yang sama. Untuk keempat jenis saluran menunjukkan frekuensi kerja yang baik pada frekuensi $650 \mathrm{MHz}$. Apabila dibandingkan dengan grafik return loss pada gambar dimana frekuensi kerja 
terbaik adalah pada frekuensi $750 \mathrm{MHz}$. Ada perbedaan sebesar $100 \mathrm{MHz}$. Walaupun demikian untuk saluran 1 sampai dengan 3 menjunkaan daya yang cukup baik pada frekuensi $725 \mathrm{MHz}$ yang berada diatas $-35 \mathrm{~dB}$. Dua frekuensi lain yang menunjukkan kinerja yang baik adalah pada frekuensi 550 $\mathrm{MHz}$ dan $460 \mathrm{MHz}$. Dengan demikian antena sangat baik bekerja pada frekuensi 460, $550 \mathrm{MHz}, 650 \mathrm{MHz}$ dan $750 \mathrm{MHz}$.

\section{Polaradiasi}

Pengukuran polaradiasi ditunjukkan pada gambar 9. sampai dengan gambar 12. Polaradiasi gambar 9 adalah polaradiasi untuk antena array dengan saluran masing-masing elemen sama panjang atau beda fasa arus masingmasing elemen adalah $0^{\circ}$. Untuk polaradiasi arah horizontal polaradiasi maksimum pada arah $60^{\circ}$ dan $240^{\circ}$. sedangkan untuk polaradiasi arah vertikal polaradiasi kelihatan maksimum pada arah $0^{\circ}, 300^{\circ}$ hingga $270^{\circ}$. secara umum polaradis di mengarah pada arah depan antena. Polaradiasi ini mendekati bentuk polaradiasi simulasi.

Dengan menggeser fasa masingmasing elemen $45^{\circ}$ atau beda saluran catu $0.125 \lambda$ dapat dilihat polaradiasi antena berubah sebagaimana yang dapat dilihat pada gambar 10 . Pengarahan yang cukup baik didapat pada polaradiasi vertikal, dimana polaradiasi mendekati polaradiasi unidirectional. Sedangkan untuk arah horizontal polaradiasi mengarah pada $210^{\circ}$ dan $240^{\circ}$. tetapi daya terima lebih rendah dibanding penerimaan arah horizontal.

Sedangkan dengan selisih saluran 0.25 $\lambda$ lamda atau masing-masing saluran berbeda fasa $90^{\circ}$ didapat polaradiasi yang mengarah pada $150^{\circ}$ secara horizontal. Sedangkan polaradiasi arah vertikan maksimum pada arah $60^{\circ}$.sebagaimana yang ditunjukkan pada gambar 11. Selanjutnya untuk antena dengan beda panjang masingmasing saluran $0.5 \lambda$ polaradiasi horizontal maupun vertikal mengarah pada $0^{\circ}$ tetapi lebar beam untuk horizontal lebih besar dibanding vertical ditunjukkan pada gambar 12 . Dengan demikian Penggeseran fasa catu antena array mikrostrip dapat mengendalikan arah maksimum pola radiasi antena. Tetapi perubahan arah radiasi tidak berbanding lurus dengan penggeseran fasa.

Pada gambar 13 dapat dilihat perbandingan daya masing antena pada arah horizontal dan arah vertical. Baik untuk arah horizontal maupun vertical level terima meningkat sesuai dengan pertambahan panjang kabel catu. Dengan demikian semakin tinggi beda fasa arus antar elemen memberikan peningkatan gain.

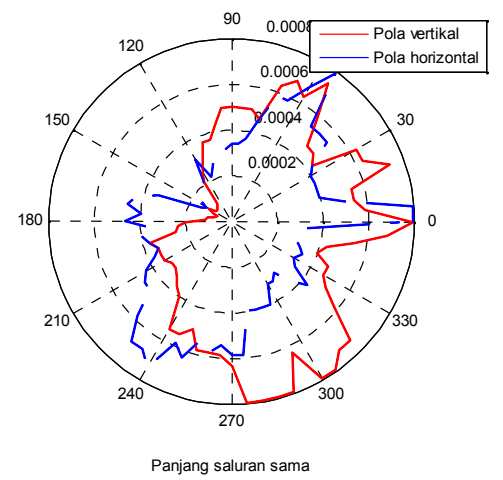

Gambar 9. Polaradiasi antena dengan panjang saluran sama.

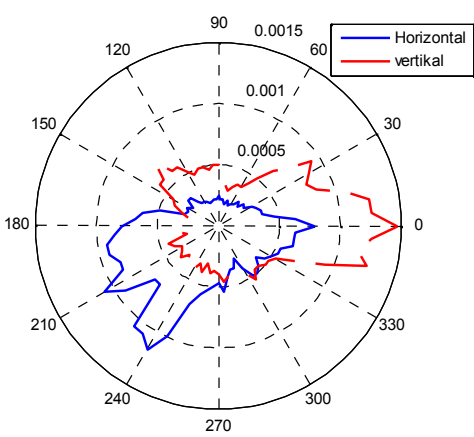


Gambar 10. Polaradiasi dengan panjang 0.125 lambda

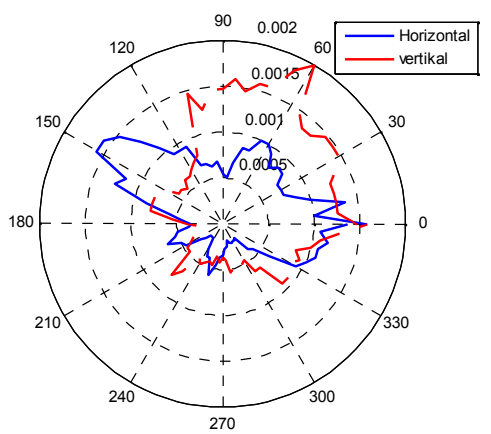

Gambar 11 Polaradiasi antena dengan beda saluran $0.25 \lambda$

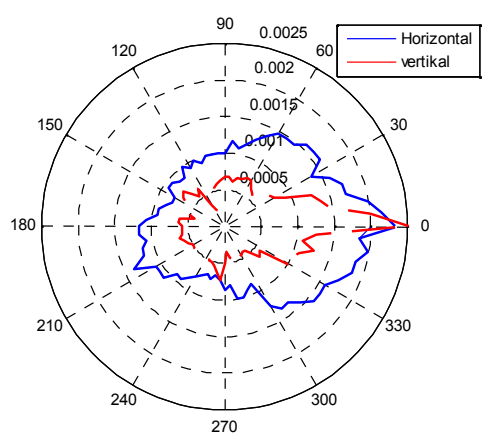

Gambar 12. Polaradiasi dengan panjang saluran 0.5 lambda

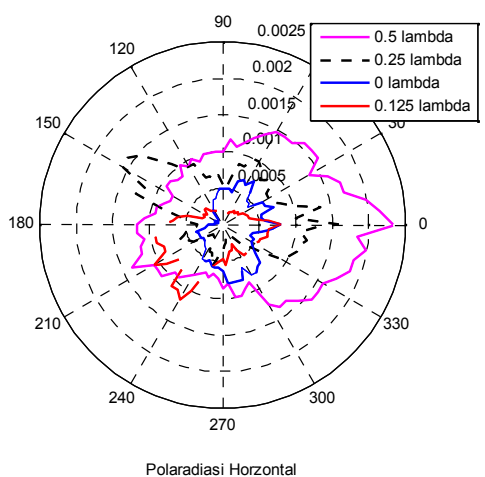

Gambar 13. Perbandingan Daya terima

\section{DAFTAR PUSTAKA}

[1] Firdaus, Yulindon, Disain dan Implementasi Antena Array 5 Elemen untuk Mendapatkan Pola Radiasi Omnidirectional dengan Penerapan pada Transmisi Broadcast.

[2] Robert R. Romanofsky,2007 "Array Phase Shifters: Theory and Technology"NASA 2007

Radar tutorial, http://www.radartutorial.eu/01.basi cs/rb05.en.html

[3] Warrant L stutmant, "Antena Theori and Design", John Willey \& Son, USA, 1981.

[4] John D. Kraus, Antennas, John Willey \& Son. 